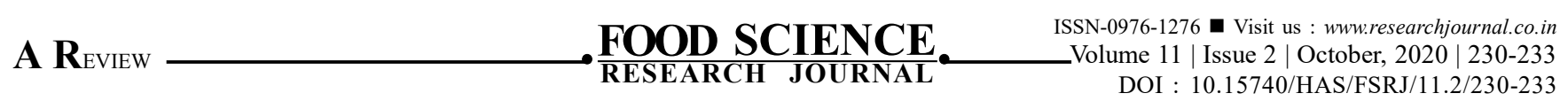

\title{
Destalking machine for chilli
}

\begin{abstract}
G. Srinivas and P.S. Champawat
This paper presents the review on chilli destalking/destemming machine with the related search. Chilli is an important spice crop and India is one of the leading producer and consigner of chilli in the world. Chilli is widely used around the world in food as a spice both in dried and fresh form which adds flavour to the meal by creating spicy pungent taste. The study specifies factors influencing the chilli destalking process and recommends a design options for destalking machine. These designs are based on a systematic study of the destalking process for dry chilli, related to which some literatures reviews and works of them are explained. The manual operated, mechanical system, sensor based and artificial neural network (ANN) based system are some of the approach been made for destalking of chilli.
\end{abstract}

Key Words : Chilli, Post harvest, Destemming, Mechanization, Destalking

How to cite this article : Srinivas, G. and Champawat, P.S. (2020). Destalking machine for chilli. Food Sci. Res. J., 11(2): 230-233, DOI : 10.15740/HAS/FSRJ/11.2/230-233.Copyright@ 2020: Hind Agri-Horticultural Society.

Author for correspondence :

G. Srinivas, Department of Processing and Food Engineering, College of Technology and Engineering (MPUAT), Udaipur (Rajasthan) India

Email: sgirjals@gmail.com

Associate Authors' :

P. S. Champawat, Department of Processing and Food Engineering, College of Technology and Engineering (MPUAT), Udaipur (Rajasthan) India 